\title{
Volatile organic compounds and lung cancer: a tight link useful for diagnosis
}

\author{
Roberto Gasparri ${ }^{1}$, Giulia Sedda ${ }^{1}$, Lorenzo Spaggiari ${ }^{1,2}$ \\ ${ }^{1}$ Department of Thoracic Surgery, IEO, European Institute of Oncology IRCCS, Milan, Italy; ${ }^{2}$ Department of Oncology and Hemato-oncology, \\ University of Milan, Milan, Italy \\ Correspondence to: Dr. Roberto Gasparri, MD, PhD. Department of Thoracic Surgery, IEO, European Institute of Oncology, Via Giuseppe Ripamonti \\ 435, Milano 20141, Italy. Email: roberto.gasparri@ieo.it.
}

Received: 09 October 2018; Accepted: 19 October 2018; Published: 14 December 2018.

doi: $10.21037 /$ shc.2018.12.07

View this article at: http://dx.doi.org/10.21037/shc.2018.12.07

The human body generates thousands of volatile organic compounds (VOCs) that can be excreted thought breath, skin, urine or feces, related to endogenous process and influenced by exogenous VOCs (1). Endogenous VOCs (e.g., isopropanol and benzene) are low molecular weight compounds produced by cell metabolism and represent the endpoint of cellular process (i.e., gene expression, mRNA transcription and protein activity). Instead, exogenous VOCs (e.g., ethane and pentane) are absorbed mostly by inhalation or ingestion and are linked to diet, environmental exposure and tobacco consumption. Upon their production, VOCs are excreted from cell into circulatory system and diffuse into the lungs, where they are exhaled. Inside breathe the most commonly identified VOCs are isoprene, acetone, ethanol, methanol, and alcohols and alkanes.

Considering that VOCs pattern composition reflect cellular metabolism, under pathophysiological condition, processes such as their adsorption, distribution, metabolism and excretion can be altered. Indeed, several studies demonstrated that VOCs variation is linked to angiogenesis, oxidative stress, Warburg effect and gene mutations. Moreover, inflammatory state or modifications in microenvironment can also influenced VOCs composition.

Lung's cancerous cells are able to affect host's metabolism pathway, have a different metabolism their self (e.g., different glucose uptake) but are able also to produce and execrate VOCs. Thus, lung cancer detection throughout VOCs pattern recognition has been investigated extensively. In vitro (e.g., headspace analysis of cell cultures) animal model investigation has been tested. Even though these fields have given useful information, data obtained have high rate of failure due to intrinsic differences compared to human body, starting from complexity to the environment influence. Considering their pathway and potentiality, many researches have been focused on VOCs analysis inside breath (2), called "Breathlomics". This is an extreme challenging field due to breath composition, which can be affected in pathological condition only in some of its components, and concentration, that is very low compared to other molecules (i.e., VOCs inside breath compared to proteins inside blood). Nevertheless, breath has several clinical characteristics that enhance its potentiality: for instance, it can be tested frequently in all the conditions, thanks to its cheapness and noninvasiveness. Indeed, several studies have detected VOCs ability not only for cancer detection but also non-oncological respiratory disease diagnosis or monitoring, such as asthma, cystic fibrosis, bacterial respiratory tract infection or chronic obstructive pulmonary disease (COPD).

The two principal approaches used for breath investigation are gas chromatography-mass spectrometry (GC-MS) and VOCs analysis with artificial intelligence system. GC-MS is able to separate VOCs by mass/ charge ratio and compare them to a library of known metabolites. Even though this technology is useful to identify specific biomarkers (i.e., quantifiable molecules related to the pathological state), its potentiality is limited due to complexity, lengthy analysis time and high cost (3). 
The artificial devices, called electronic nose (or e-nose), are small portable devices, composed of non-selective sensors which are able to respond at pattern concentration variation. E-noses have been compared to the mammalian olfactory system, in particular to canine's nose ability to detect cancer. The first scientific report of sniffer dog has been published in 1989 about dog's melanoma detection on his owner's leg. From this first finding, several studies described dog's ability to detect different type of cancer by sniffing, including bladder, breast, prostate and ovarian. Ehmann and colleagues (4) demonstrated that lung cancer VOCs signature is independent from other bias (e.g., COPD, tobacco smoke and food odors) and dogs are able to distinguish lung cancer from breath analysis despite any comorbidities or smoking status. The e-nose response to the VOCs pattern is translated into a digital curve or fingerprint called "breathprint". This curve is compared with multicomponent statistical analysis to a library of healthy subject's fingerprint, to highlight any variation from the standard. The "breathprint" is considered a biomarker of the disease and has been tested for lung cancer diagnosis, disease progression monitoring and response to treatment. Each disease phase theoretically could be characterized by a different VOCs pattern, thus a pre-post treatment analysis is mandatory. Moreover, this could also allow applying VOCs diagnostic to discriminate any recurrence of the disease. Other type of technologies applied to VOC analysis are proton transfer reaction mass spectrometry, selected ion flow tube mass spectrometry, multi-capillary column ion mobility spectrometry.

Lung cancer poor prognosis, linked to advanced diagnosis, reliable screening methods to detect lung cancers at an early stage are highly important and justify all these effort. Even though all these findings are promising, there are still several steps that prevent the translation to clinical practice (5). Human body complexity, which reflects VOCs profile composition, is still beyond the capabilities of current technology. Moreover, patients' recruiting and breath collection are still need high standardization. Large cohort of well-selected patients compared to healthy subjects, bearing in mind their intrinsic diversity, are the next step that VOCs research need to achieve. This would allow generating a detailed library of VOCs profile and improving clinical diagnosis.

\section{Acknowledgments}

Funding: None.

\section{Footnote}

Provenance and Peer Review: This article was commissioned by the editorial office, Shanghai Chest. The article did not undergo external peer review.

Conflicts of Interest: All authors have completed the ICMJE uniform disclosure form (available at http://dx.doi. org/10.21037/shc.2018.12.07). The authors have no conflicts of interest to declare.

Ethical Statement: The authors are accountable for all aspects of the work in ensuring that questions related to the accuracy or integrity of any part of the work are appropriately investigated and resolved.

Open Access Statement: This is an Open Access article distributed in accordance with the Creative Commons Attribution-NonCommercial-NoDerivs 4.0 International License (CC BY-NC-ND 4.0), which permits the noncommercial replication and distribution of the article with the strict proviso that no changes or edits are made and the original work is properly cited (including links to both the formal publication through the relevant DOI and the license). See: https://creativecommons.org/licenses/by-nc-nd/4.0/.

\section{References}

1. Haick H, Broza YY, Mochalski P, et al. Assessment, origin, and implementation of breath volatile cancer markers. Chem Soc Rev 2014;43:1423-49.

2. Nardi-Agmon I, Peled N. Exhaled breath analysis for the early detection of lung cancer: recent developments and future prospects. Lung Cancer (Auckl) 2017;8:31-8.

3. Dragonieri S, Schot R, Mertens BJ, et al. An electronic nose in the discrimination of patients with asthma and controls. J Allergy Clin Immunol 2007;120:856-62.

4. Ehmann R, Boedeker E, Friedrich U, et al. Canine scent detection in the diagnosis of lung cancer: revisiting a puzzling phenomenon. Eur Respir J 2012;39:669-76.

5. Horváth I, Barnes PJ, Loukides S, et al. A European Respiratory Society technical standard: exhaled biomarkers in lung disease. Eur Respir J 2017;49(4).

doi: $10.21037 /$ shc.2018.12.07

Cite this article as: Gasparri R, Sedda G, Spaggiari L. Volatile organic compounds and lung cancer: a tight link useful for diagnosis. Shanghai Chest 2018;2:95. 